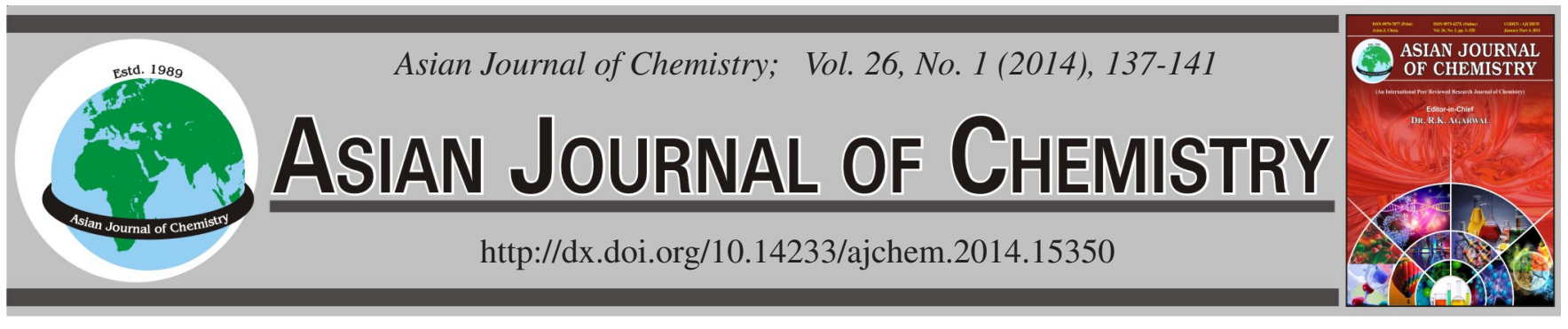

\title{
Intermolecular Interaction Studies in Binary Mixture of Methyl formate with Methanol at Various Temperatures
}

\author{
S. Elangovan ${ }^{1,2, *}$ and S. Mullainathan ${ }^{2,3}$
}

${ }^{1}$ Department of Physics, Easwari Engineering College, Chennai-600 089, India

${ }^{2}$ Research and Development Centre, Bharathiar University, Coimbatore-641 046, India

${ }^{3}$ Department of Physics, A.V.C. College of Engineering, Mayiladuthurai-609 305, India

*Corresponding author: E-mail: elangovan.physics@ rediffmail.com

Received: 18 February 2013;

Accepted: 27 June 2013;

Published online: 26 December 2013;

AJC-14489

Density $(\rho)$, viscosity $(\eta)$ and ultrasonic velocity $(U)$ have been measured for a binary mixture composed of methyl formate and methanol at 303,308 and $313 \mathrm{~K}$. The adiabatic compressibility $(\beta)$, acoustic impedance $(\mathrm{Z})$, free length $\left(\mathrm{L}_{\mathrm{f}}\right)$, free volume $\left(\mathrm{V}_{\mathrm{f}}\right)$, internal pressure $\left(\pi_{\mathrm{i}}\right)$, viscous relaxation time $(\tau)$ and Gibbs free energy $(\Delta G)$ have been calculated from the experimental data. The excess values of these parameters $\left(\beta^{\mathrm{E}}, \mathrm{Z}^{\mathrm{E}}, \mathrm{L}_{\mathrm{f}}^{\mathrm{E}}, \mathrm{V}_{\mathrm{f}}^{\mathrm{E}}, \pi_{\mathrm{i}}^{\mathrm{E}}, \tau^{\mathrm{E}}\right.$ and $\left.\Delta \mathrm{G}^{\mathrm{E}}\right)$ have also been calculated by using the determined data and interpreted in terms of molecular interactions. The deviations in the sign and values of these excess parameters from the ideal mixing reveal that intermolecular interactions obtaining in the liquid mixture.

Keywords: Methyl formate, Methanol, Ultrasonic velocity, Hydrogen bonding.

\section{INTRODUCTION}

Molecular interaction studies in liquid mixtures have significant relevance in many field of applied and theoretical research. Such studies have shown the structure and bonding of associated molecular complex in the binary and ternary mixture ${ }^{1-5}$. Ultrasonic velocity in a liquid mixture is fundamentally related with the binding forces acting between the atoms or molecules present in the liquid system. It is one of the sensitive techniques to elucidate the intermolecular interaction between the liquid systems ${ }^{6,7}$. Methyl formate is used in the lacquer industry as a solvent for cellulose nitrate. It is also used as a fumigant and larvacide for tobacco. The molecular interaction studies of liquid mixtures with alcohols as one of the components is of particular interest, since alcohols are highly polar and self associated through hydrogen bonding in pure state ${ }^{8,9}$. Excess molar volumes and viscosities for binary mixtures of butyrolactone with methyl formate, ethyl formate, methyl acetate, ethyl acetate and acetonitrile at 298.15 K have reported by Lu et al $^{10}$. Excess molar enthalpies of ethyl formate and 1-propanol, 2-propanol, 1-butanol and 2-butanol and 1 -pentanol at $308.15 \mathrm{~K}$ have reported by Dong et al. ${ }^{11}$. The survey of literature indicate that there are no reports on molecular interaction studies of the methyl formate with methanol in the present study.

The present work is an attempt to elucidate the molecular interaction between methyl formate and methanol at $303 \mathrm{~K}$, $308 \mathrm{~K}$ and $313 \mathrm{~K}$ by using ultrasonic technique.
Using the experimental data, the following acoustical parameters have been calculated.

$$
\text { Ultrasonic wavelength }(\lambda)=\frac{2 d}{n}
$$

where $d$ is the distance moved by the reflector and $n$ is the number of oscillation produced by the ultrasonic interferometer.

$$
\text { Ultrasonic velocity }(\mathrm{U})=\mathrm{f} \lambda
$$

where, $\mathrm{f}$ is the frequency of ultrasonic wave.

$$
\text { Adiabatic compressibility }(\beta)=\frac{1}{\mathrm{U}^{2} \rho}
$$

where, $\rho$ represents density of the liquid mixture.

Acoustic impedance $(Z)=U \rho$

Inter molecular free length $\left(\mathrm{L}_{\mathrm{f}}\right)=\mathrm{K}_{\mathrm{T}} \sqrt{\beta}$

where $\mathrm{K}_{\mathrm{T}}$ is a temperature dependent constant ${ }^{12}$ and is given as, $\mathrm{K}_{\mathrm{T}}=(93.875+0.375 \mathrm{~T}) \times 10^{-8}$ kelvin

Suryanarayana et $a l .{ }^{13}$. have related the free volume in terms of ultrasonic velocity (U) and co efficient of viscosity $(\eta)$ as given below,

$$
\text { Free volume }\left(V_{f}\right)=\left[\frac{M_{e f} U}{\eta K}\right]^{3 / 2}
$$

Here $\mathrm{M}_{\text {eff }}$ is the effective molecular weight; $\mathrm{K}$ is a temperature independent constant which is equal to $4.281 \times 10^{9}$ in S.I units for all liquid systems. 


$$
\text { Internal Pressure }\left(\pi_{\mathrm{i}}\right)=\mathrm{bRT}\left[\frac{\mathrm{K} \eta}{\mathrm{U}}\right]^{1 / 2}\left[\frac{\rho^{2 / 3}}{\mathrm{M}_{\mathrm{eff}}^{7 / 6}}\right]
$$

Where $\mathrm{b}$ is a cubical packing fraction and is equal to 2 for all liquids. $\mathrm{R}$ is the universal gas constant, $\mathrm{T}$ is the experimental temperature and $\mathrm{K}$ is the temperature independent constant.

$$
\begin{aligned}
& \text { The viscous relaxation time }(\tau)=\frac{4}{3} \beta \eta \\
& \text { Gibbs free energy }(\Delta \mathrm{G})=\mathrm{kT} \ln \left(\frac{\mathrm{kT} \tau}{\mathrm{h}}\right)
\end{aligned}
$$

where $\mathrm{k}$ is Boltzmann constant; $\mathrm{T}$ is absolute temperature and $\mathrm{h}$ is Planck's constant.

Excess parameters have been calculated using the following relation

$$
\begin{array}{lr}
A^{E}=A_{\text {exp }}-A_{i} \\
\text { Here } & A_{\text {id }}=\Sigma A_{i} X_{i}
\end{array}
$$

$A_{i}$ represents any acoustical parameter and $x_{i}$ is the corresponding mole fraction.

In all the mixtures $\mathrm{x}_{1}$ and $\mathrm{x}_{2}$ are represented the mole fraction of methyl formate and methanol, respectively.

\section{EXPERIMENTAL}

Binary mixtures are prepared by mixing appropriate volume of the liquid components in the standard flasks with air tight caps. The masses are recorded on digital electronic balance (ACM-78094L,ACMAS Ltd, India) to an uncertainty of $\pm 1 \mathrm{mg}$. The density and viscosity are measured by using specific gravity bottle and Ostwald's viscometer with accuracy $\pm 0.01 \mathrm{~kg} \mathrm{~m}^{-3}$ and $\pm 0.001 \mathrm{Ns} \mathrm{m}^{-2}$, respectively. The ultrasonic velocities in the liquid mixtures are measured by using a single crystal ultrasonic interferometer (Mittal Enterprises, New Delhi Model: f81) operated at $2 \mathrm{MHz}$, which is calibrated with water. The accuracy in the ultrasonic velocity measurement is in the order of $\pm 1 \mathrm{~m} \mathrm{~s}^{-1}$. All measurements are made using a constant temperature bath [INSREF model IRI-016C, India] by circulating water from the thermostat with accuracy $\pm 0.01 \mathrm{~K}$. In the present study the chemicals used are of Analytical Grade (AR) purchased from $\mathrm{Sd}$ fine Chemicals, India. All the liquids are used without further purification. The purity of the chemicals is checked by comparing the density $(\rho)$, viscosity $(\eta)$ and ultrasonic velocity $(\mathrm{U})$ with available literature data ${ }^{14,15}$ and listed in Table-1.

\section{RESULTS AND DISCUSSION}

The experimentally measured values of density $(\rho)$, viscosity $(\eta)$, ultrasonic velocity $(\mathrm{U})$ and computed values of adiabatic compressibility $(\beta)$, acoustic impedance $(Z)$, free length $\left(L_{f}\right)$, free volume $\left(\mathrm{V}_{\mathrm{f}}\right)$, internal pressure $\left(\pi_{\mathrm{i}}\right)$, viscous relaxation time $(\tau)$, Gibbs free energy $(\Delta \mathrm{G})$ for a binary mixture of methyl formate and methanol at $303 \mathrm{~K}, 308 \mathrm{~K}$ and $313 \mathrm{~K}$ are listed in Table-2.

Table-2 shows that the density of the binary mixtures decreases with increasing mole fraction of the methyl formate. This trend may suggest that the increasing concentration of the methyl formate leads to decrease the number of particles in a given region ${ }^{16}$. The decreasing trend of viscosity with increasing mole fraction of methyl formate is due to that the intermolecular interaction between the methyl formate and methanol is weakend. The decrease in density and viscosity with increase in temperature indicating loosening of intermolecular forces due to thermal agitation of molecules in the mixture. In this present study, ultrasonic velocity decreased with increasing concentration of methyl formate (Fig. 1). Moreover acoustic impedance shows the same trend of ultrasonic velocity. It may be due to the structural changes occurring in the mixtures resulting in weakening of intermolecular

\begin{tabular}{|c|c|c|c|c|c|c|c|c|}
\hline \multirow{3}{*}{ Liquid } & \multicolumn{7}{|c|}{$\begin{array}{l}\text { TABLE-1 } \\
\text { COMPARISON OF EXPERIMENTAL DENSITY }(\rho) \text {, VISCOSITY ( } \eta \text { ) AND ULTRASONIC VELOCITY (U) } \\
\text { OF PURE COMPONENTS WITH AVAILABLE LITERATURE VALUES AT 303, } 308 \text { AND } 313 \mathrm{~K}\end{array}$} & \multirow{3}{*}{ Ref. } \\
\hline & \multirow{2}{*}{$\begin{array}{c}\text { Temperature (T) } \\
(\mathrm{K})\end{array}$} & \multicolumn{2}{|c|}{ Density $(\rho)\left(\mathrm{kg} \mathrm{m}^{-3}\right)$} & \multicolumn{2}{|c|}{ Viscosity $(\eta) \times 0^{-3}\left(\mathrm{Ns} \mathrm{m}^{-2}\right)$} & \multicolumn{2}{|c|}{ Ultrasonic velocity $(\mathrm{U})\left(\mathrm{m} \mathrm{s}^{-1}\right)$} & \\
\hline & & Expt. & Lit. & Expt. & Lit. & Expt. & Lit. & \\
\hline \multirow{3}{*}{ Methanol } & 303 & 781.9 & 782.4 & 0.4958 & 0.5040 & 1087 & 1088 & [14] \\
\hline & 308 & 776.5 & 777.2 & 0.4695 & 0.4747 & 1109 & 1108 & [14] \\
\hline & 313 & 771.2 & 771.9 & 0.3901 & 0.3892 & 1137 & 1137 & [14] \\
\hline \multirow{3}{*}{$\begin{array}{l}\text { Methyl } \\
\text { formate }\end{array}$} & 303 & 958.9 & 958.1 & 0.3210 & 0.3230 & 1068 & - & [15] \\
\hline & 308 & 953.6 & - & 0.3147 & - & 1050 & - & \\
\hline & 313 & 947.8 & - & 0.3075 & - & 1028 & - & \\
\hline
\end{tabular}
forces.

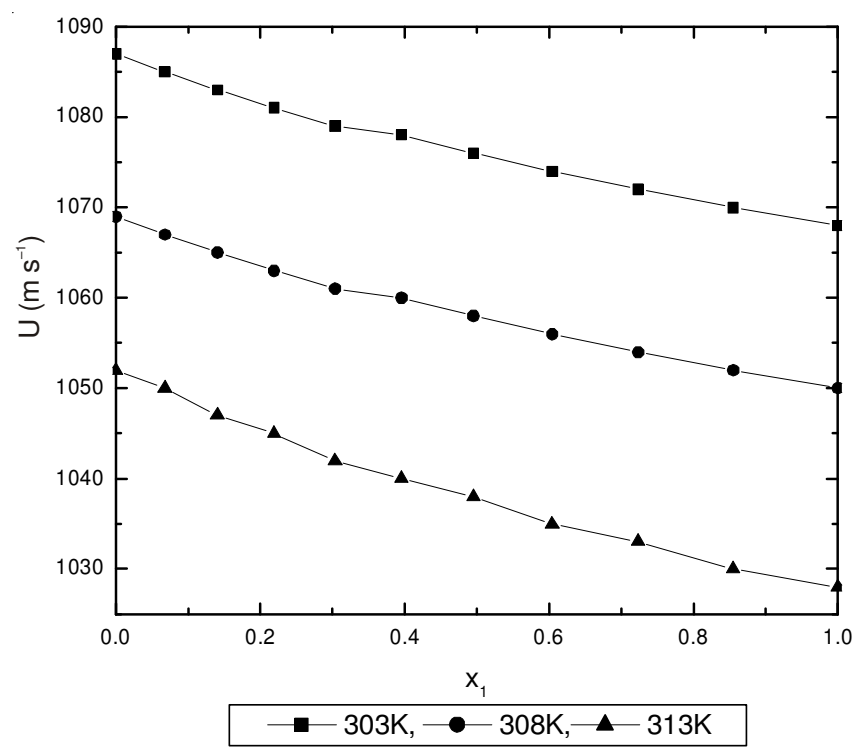

Fig. 1. Plots of ultrasonic velocity variation versus mole fraction of methyl formate at various temperatures 
PHYSICAL AND ACOUSTICAL PARAMETERS OF METHYL FORMATE + METHANOL AT 303, 308 AND 313 K

\begin{tabular}{|c|c|c|c|c|c|c|c|c|c|c|}
\hline $\mathrm{x}_{1}$ & $\begin{array}{c}\rho \\
\left(\mathrm{kg} \mathrm{m}^{-3}\right)\end{array}$ & $\begin{array}{l}\eta \times 10^{-3} \\
\left(\mathrm{Ns} \mathrm{m}^{-2}\right)\end{array}$ & $\mathrm{U}\left(\mathrm{m} \mathrm{s}^{-1}\right)$ & $\begin{array}{l}\beta \times 10^{-10} \\
\left(\mathrm{~m}^{2} \mathrm{~N}^{-1}\right)\end{array}$ & $\begin{array}{c}\mathrm{Z} \times 10^{6} \\
\left(\mathrm{~kg} \mathrm{~m}^{-2} \mathrm{~s}^{-1}\right)\end{array}$ & $\begin{array}{c}\mathrm{L}_{\mathrm{f}} \times 10^{-10} \\
(\mathrm{~m})\end{array}$ & $\begin{array}{c}\mathrm{V}_{\mathrm{f}} \times 10^{-7} \\
\left(\mathrm{~m}^{3} \mathrm{~mol}^{-1}\right)\end{array}$ & $\begin{array}{l}\pi_{\mathrm{I}} \times 10^{9} \\
\left(\mathrm{Nm}^{-2}\right)\end{array}$ & $\begin{array}{c}\tau \times 10^{-12} \\
(\mathrm{~s})\end{array}$ & $\begin{array}{c}\Delta \mathrm{G} \times 10^{-20} \\
\left(\mathrm{kJmol}^{-1}\right)\end{array}$ \\
\hline \multicolumn{11}{|c|}{$303 \mathrm{~K}$} \\
\hline 0.0000 & 781.9 & 0.4958 & 1087 & 10.8241 & 0.8499 & 0.6827 & 0.6647 & 1.8634 & 0.7155 & 0.6304 \\
\hline 0.0677 & 799.6 & 0.4783 & 1085 & 10.6240 & 0.8676 & 0.6763 & 0.7626 & 1.7555 & 0.6775 & 0.6076 \\
\hline 0.1405 & 817.3 & 0.4608 & 1083 & 10.4327 & 0.8851 & 0.6702 & 0.8777 & 1.6509 & 0.6410 & 0.5844 \\
\hline 0.2189 & 835.0 & 0.4434 & 1081 & 10.2490 & 0.9026 & 0.6643 & 1.0135 & 1.5496 & 0.6059 & 0.5609 \\
\hline 0.3036 & 852.7 & 0.4259 & 1079 & 10.0732 & 0.9201 & 0.6586 & 1.1753 & 1.4513 & 0.5720 & 0.5368 \\
\hline 0.4952 & 888.1 & 0.3909 & 1076 & 9.7255 & 0.9556 & 0.6471 & 1.6039 & 1.2634 & 0.5069 & 0.4863 \\
\hline 0.6041 & 905.8 & 0.3734 & 1074 & 9.5710 & 0.9728 & 0.6419 & 1.8867 & 1.1743 & 0.4765 & 0.4604 \\
\hline 0.7234 & 923.5 & 0.3560 & 1072 & 9.4227 & 0.9900 & 0.6370 & 2.2314 & 1.0883 & 0.4473 & 0.4339 \\
\hline 0.8548 & 941.2 & 0.3385 & 1070 & 9.2801 & 1.0078 & 0.6321 & 2.6577 & 1.0050 & 0.4188 & 0.4065 \\
\hline 1.0000 & 958.9 & 0.3210 & 1068 & 9.1429 & 1.0240 & 0.6274 & 3.1882 & 0.9247 & 0.3913 & 0.3780 \\
\hline \multicolumn{11}{|c|}{$308 \mathrm{~K}$} \\
\hline 0.0000 & 776.5 & 0.4695 & 1069 & 11.2695 & 0.8301 & 0.7029 & 0.7035 & 1.0384 & 0.7055 & 0.6248 \\
\hline 0.2189 & 829.6 & 0.4231 & 1063 & 10.6676 & 0.8819 & 0.6838 & 1.0603 & 0.8422 & 0.6018 & 0.5583 \\
\hline 0.3036 & 847.3 & 0.4076 & 1061 & 10.4841 & 0.8990 & 0.6779 & 1.2240 & 0.7821 & 0.5698 & 0.5354 \\
\hline 0.3954 & 865.1 & 0.3921 & 1060 & 10.2878 & 0.9170 & 0.6716 & 1.4207 & 0.7243 & 0.5378 & 0.5112 \\
\hline 0.4952 & 882.8 & 0.3766 & 1058 & 10.1197 & 0.9340 & 0.6661 & 1.6537 & 0.6693 & 0.5081 & 0.4875 \\
\hline 0.6041 & 900.5 & 0.3611 & 1056 & 9.9583 & 0.9509 & 0.6607 & 1.9342 & 0.6167 & 0.4794 & 0.4631 \\
\hline 0.7234 & 918.2 & 0.3457 & 1054 & 9.8035 & 0.9678 & 0.6556 & 2.2734 & 0.5665 & 0.4519 & 0.4384 \\
\hline 0.8548 & 935.9 & 0.3302 & 1052 & 9.6547 & 0.9846 & 0.6506 & 2.6892 & 0.5185 & 0.4251 & 0.4129 \\
\hline 1.0000 & 953.6 & 0.3147 & 1050 & 9.5116 & 1.0013 & 0.6457 & 3.2018 & 0.4727 & 0.3991 & 0.3865 \\
\hline \multicolumn{11}{|c|}{$313 \mathrm{~K}$} \\
\hline 0.0000 & 771.2 & 0.3901 & 1052 & 11.7166 & 0.8113 & 0.7231 & 0.9067 & 0.9652 & 0.6094 & 0.5959 \\
\hline 0.0677 & 788.9 & 0.3818 & 1050 & 11.4974 & 0.8283 & 0.7163 & 1.0179 & 0.9074 & 0.5853 & 0.5784 \\
\hline 0.1405 & 806.5 & 0.3736 & 1047 & 11.3110 & 0.8444 & 0.7105 & 1.1429 & 0.8522 & 0.5634 & 0.5620 \\
\hline 0.2189 & 824.2 & 0.3653 & 1045 & 11.1105 & 0.8613 & 0.7041 & 1.2882 & 0.7986 & 0.5411 & 0.5446 \\
\hline 0.3036 & 841.8 & 0.3571 & 1042 & 10.9410 & 0.8772 & 0.6988 & 1.4527 & 0.7475 & 0.5209 & 0.5281 \\
\hline 0.3954 & 859.5 & 0.3488 & 1040 & 10.7569 & 0.8939 & 0.6929 & 1.6456 & 0.6979 & 0.5003 & 0.5106 \\
\hline 0.7234 & 912.5 & 0.3240 & 1033 & 10.2699 & 0.9426 & 0.6770 & 2.4311 & 0.5606 & 0.4436 & 0.4588 \\
\hline 0.8548 & 930.1 & 0.3158 & 1030 & 10.1344 & 0.9580 & 0.6725 & 2.7855 & 0.5186 & 0.4267 & 0.4420 \\
\hline 1.0000 & 947.8 & 0.3075 & 1028 & 9.9838 & 0.9743 & 0.6675 & 3.2113 & 0.4779 & 0.4093 & 0.4240 \\
\hline
\end{tabular}

The increasing trend in adiabatic compressibility with increasing concentration of methanol show that the medium is more and more easily compressed. The increasing trend of free volume indicates the carbonyl group of methyl formate and hydroxyl group present in the methanol can mutually form dipoles and this dipolar interaction also supports the existence of more space between the components. The intermolecular free length supports the same trend ${ }^{17}$. Obviously reverse trend is obtained in the internal pressure as listed in Table-2. The viscous relaxation time decreases with increase in mole fraction of methyl formate. Moreover the reduction of Gibbs free energy in the liquid mixture indicates that the need less time for the rearrangement of the molecules in the liquid mixture decreases the energy that leads to dissociation ${ }^{18}$.

In order to elucidate the nature of molecular interactions between the components of the liquid mixtures, it is of considerable interest to study the excess parameters rather than actual values ${ }^{19}$. Non-ideal liquid mixtures show the significant deviation from linearity in their physical behavior with respect to the concentration and temperature is interoperated the presence of strong or weak interactions.

The excess values of $\beta^{\mathrm{E}}, \mathrm{L}_{\mathrm{f}}^{\mathrm{E}}, \mathrm{V}_{\mathrm{f}}^{\mathrm{E}}, \tau^{\mathrm{E}}$ and $\Delta \mathrm{G}^{\mathrm{E}}$ are listed in Table-3. The positive excess values represent the dispersion forces, while the negative values interpreted that the dipole- dipole, charge transfer interaction and hydrogen bonding between the unlike molecules ${ }^{20}$.

Fort et al..$^{20}$ suggested that the values of excess compressibility become increasingly negative with increase in the strength of molecular interaction of binary liquid mixtures. The perusal of Table- 3 signifies that the excess compressibility $\beta^{\mathrm{E}}$ values are negative over the entire range of composition at 303, 308 and $313 \mathrm{~K}$. Moreover those values are increased in the lower concentrations and decreased in the higher concentrations of methyl formate. The negative values may be attributed to the existence of the dispersion and dipolar interaction between the unlike molecules.

In this present study excess free length $\mathrm{L}_{\mathrm{f}}^{\mathrm{E}}$ support the same trend of excess adiabatic compressibility (Table-3). The increasing negative values signify that the strength of molecular interaction increased with increasing temperature and the concentration of methyl formate.

The variation in the negative excess free volume against the mole fraction of methyl formate is plotted (Fig. 2). It shows that the negative excess free volume increases up to a critical mole fraction of methyl formate $\left(\mathrm{x}_{1}=0.3954\right)$ then decreased in the higher concentration. Thus, the observed negative values of excess free volume can be accounted for only by considering the predominance of an energetically favoured hydrogen bonding 


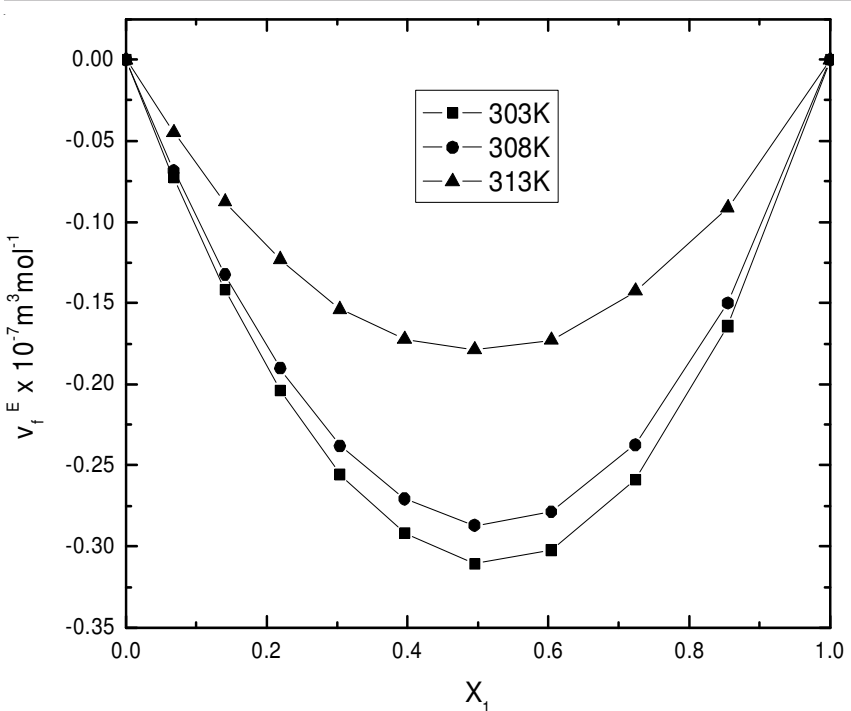

Fig. 2. Plots of excess free volume versus mole fraction of methyl formate at different temperatures

$(-\mathrm{OH}---\mathrm{O}=\mathrm{C})$ formed in the liquid system. The higher concentration $\left(\mathrm{x}_{1}>0.3954\right)$ of methyl formate rupture of hydrogen bonding associate with methanol. The similar result has obtained and reported by Rathore et al..$^{21}$.

Table- 3 reveals that the negative values of excess relaxation time $\tau^{\mathrm{E}}$ and excess Gibbs free energy $\Delta \mathrm{G}^{\mathrm{E}}$ increased with the increasing at the lower concentrations of methyl formate. It is suggested that the molecules get rearranged due to cooperative process. Similar results have been reported by Pradhan et $a .^{22}$. This trend may suggested the thermal agitation of the liquid system in the higher temperatures.

\section{Conclusion}

From the experimental observation, the physical and acoustical parameters were determined in the binary mixture of methyl formate and methanol at 303, 308 and $313 \mathrm{~K}$. The calculated excess values and their sign show the specific hydrogen bonding interaction obtained in the carbonyl group of the methyl formate and hydroxyl group present in the methanol. Moreover sound velocity is in the order of $303>$ $308>313 \mathrm{~K}$. The decrease in ultrasonic velocity with increase in temperature at any concentration signifies that decrease in intermolecular forces due to increase in thermal energy of the liquid system.

TABLE-3

EXCESS PARAMETERS OF THE BINARY MIXTURE OF METHYL FORMATE + METHANOL AT 303, 308 AND 313 K

\begin{tabular}{|c|c|c|c|c|c|c|c|}
\hline $\mathrm{x}_{1}$ & $\begin{array}{l}\beta^{\mathrm{E}} \times 10^{-10} \\
\left(\mathrm{~m}^{2} \mathrm{~N}^{-1}\right)\end{array}$ & $\begin{array}{c}\mathrm{Z}^{\mathrm{E}} \times 10^{7} \\
\left(\mathrm{~kg} \mathrm{~m}^{-2} \mathrm{~s}^{-1}\right)\end{array}$ & $\begin{array}{c}\mathrm{L}_{\mathrm{f}}^{\mathrm{E}} \times 10^{-12} \\
(\mathrm{~m})\end{array}$ & $\begin{array}{l}\mathrm{V}_{\mathrm{f}}^{\mathrm{E}} \times 10^{-7} \\
\left(\mathrm{~m}^{3} \mathrm{~mol}^{-1}\right)\end{array}$ & $\begin{array}{l}\pi_{\mathrm{i}}^{\mathrm{E}} \times 10^{8} \\
\left(\mathrm{~N} \mathrm{~m}^{-2}\right)\end{array}$ & $\begin{array}{c}\tau^{\mathrm{E}} \times 10^{-13} \\
(\mathrm{~s})\end{array}$ & $\begin{array}{c}\Delta \mathrm{G}^{\mathrm{E}} \times 10^{-21} \\
\left(\mathrm{~kJ} \mathrm{~mol}^{-1}\right)\end{array}$ \\
\hline \multicolumn{8}{|c|}{$303 \mathrm{~K}$} \\
\hline 0.0000 & 0.0000 & 0.0000 & 0.0000 & 0.0000 & 0.0000 & 0.0000 & 0.0000 \\
\hline 0.0677 & -0.0863 & 0.0591 & -0.2656 & -0.0729 & -0.4435 & -0.1605 & -0.0571 \\
\hline 0.1405 & -0.1552 & 0.1074 & -0.4730 & -0.1416 & -0.8061 & -0.2895 & -0.1054 \\
\hline 0.2189 & -0.2071 & 0.1459 & -0.6295 & -0.2036 & -1.0832 & -0.3863 & -0.1425 \\
\hline 0.3036 & -0.2405 & 0.1734 & -0.7311 & -0.2555 & -1.2711 & -0.4507 & -0.1697 \\
\hline 0.3954 & -0.2729 & 0.1956 & -0.8434 & -0.2918 & -1.3674 & -0.4901 & -0.1920 \\
\hline 0.4952 & -0.2661 & 0.1949 & -0.8215 & -0.3104 & -1.3516 & -0.4806 & -0.1911 \\
\hline 0.6041 & -0.2375 & 0.1773 & -0.7393 & -0.3024 & -1.2203 & -0.4315 & -0.1753 \\
\hline 0.7234 & -0.1852 & 0.1416 & -0.5696 & -0.2588 & -0.9604 & -0.3367 & -0.1391 \\
\hline 0.8548 & -0.1069 & 0.0908 & -0.3330 & -0.1641 & -0.5600 & -0.1957 & -0.0815 \\
\hline 1.0000 & 0.0000 & 0.0000 & 0.0000 & 0.0000 & 0.0000 & 0.0000 & 0.0000 \\
\hline \multicolumn{8}{|c|}{$308 \mathrm{~K}$} \\
\hline 0.0677 & -0.0909 & 0.0571 & -0.2728 & -0.0684 & -0.2990 & -0.1526 & -0.0587 \\
\hline 0.1405 & -0.1633 & 0.1055 & -0.4863 & -0.1324 & -0.5412 & -0.2755 & -0.1062 \\
\hline 0.2189 & -0.2171 & 0.1432 & -0.6579 & -0.1901 & -0.7237 & -0.3663 & -0.1434 \\
\hline 0.3036 & -0.2517 & 0.1692 & -0.7634 & -0.2380 & -0.8455 & -0.4268 & -0.1705 \\
\hline 0.3954 & -0.2866 & 0.1921 & -0.8683 & -0.2706 & -0.9042 & -0.4655 & -0.1938 \\
\hline 0.4952 & -0.2793 & 0.1912 & -0.8475 & -0.2870 & -0.8897 & -0.4567 & -0.1929 \\
\hline 0.6041 & -0.2493 & 0.1738 & -0.7645 & -0.2785 & -0.7996 & -0.4100 & -0.1774 \\
\hline 0.7234 & -0.1943 & 0.1385 & -0.5922 & -0.2374 & -0.6267 & -0.3195 & -0.1401 \\
\hline 0.8548 & -0.1121 & 0.0816 & -0.3405 & -0.1498 & -0.3634 & -0.1849 & -0.0820 \\
\hline 1.0000 & 0.0000 & 0.0000 & 0.0000 & 0.0000 & 0.0000 & 0.0000 & 0.0000 \\
\hline \multicolumn{8}{|c|}{$313 \mathrm{~K}$} \\
\hline 0.0000 & 0.0000 & 0.0000 & 0.0000 & 0.0000 & 0.0000 & 0.0000 & 0.0000 \\
\hline 0.0677 & -0.1019 & 0.0596 & -0.3036 & -0.0448 & -0.2481 & -0.1055 & -0.0586 \\
\hline 0.1405 & -0.1621 & 0.1020 & -0.4788 & -0.0876 & -0.4453 & -0.1789 & -0.0975 \\
\hline 0.2189 & -0.2268 & 0.1432 & -0.6829 & -0.1230 & -0.5993 & -0.2450 & -0.1367 \\
\hline 0.4952 & -0.2780 & 0.1848 & -0.8467 & -0.1786 & -0.7369 & -0.3001 & -0.1768 \\
\hline 0.6041 & -0.2372 & 0.1633 & -0.7212 & -0.1729 & -0.6612 & -0.2632 & -0.1556 \\
\hline 0.7234 & -0.1932 & 0.1339 & -0.5879 & -0.1427 & -0.5209 & -0.2105 & -0.1275 \\
\hline 0.8548 & -0.1010 & 0.0737 & -0.3073 & -0.0912 & -0.3006 & -0.1165 & -0.0696 \\
\hline 1.0000 & 0.0000 & 0.0000 & 0.0000 & 0.0000 & 0.0000 & 0.0000 & 0.0000 \\
\hline
\end{tabular}




\section{ACKNOWLEDGEMENTS}

The authors thank the Principal, Easwari Engineering College, Chennai, India for providing the necessary facilities in the Research and Development Center at Physics Department.

\section{REFERENCES}

1. J.G. Baragi, S. Maganur, V. Malode and S.J. Baragi, J. Mol. Liq., 178, 175 (2013)

2. A.K. Nain, J. Chem. Thermodyn., 60, 105 (2013).

3. F. Amireche-Ziar, D. Richon and F.B. Belaribi, Fluid Phase Equilib., 337, 255 (2013).

4. S. Elangovan and S. Mullainathan, Indian J. Phys., 86, 727 (2012).

5. G. Arivazhagan, M. Mahalakshmi and S.A. Jeenathus Zahira, Indian J. Phys., 86, 493 (2012).

6. G. Nath and R. Paikaray, Indian. J. Phys., 83, 1309 (2009).

7. A. Pal, R. Gaba and H. Kumar, J. Solution Chem., 40, 786 (2011).

8. E. Zorebski and A. Przybyla, J. Chem. Thermodyn., 59, 127 (2013).

9. A.K. Nain, J. Solution Chem., 36, 497 (2007).
10. H. Lu, J. Wang, Y. Zhao, X. Xuan and K. Zhuo, J. Chem. Eng. Data, 46, 631 (2001).

11. H. Dong, R. Zhang, W. Yan and S. Li, J. Chem. Thermodyn., 38, 113 (2006).

12. B. Jacobson, J. Chem. Phys., 20, 927 (1952).

13. C.V. Suryanarayana and T. Kuppusamy, J. Acout. Soc. Ind., 4, 75 (1976).

14. A.N. Kannappan, S. Thirumaran and R. Palani, J. Phys. Sci., 20, 97 (2009).

15. M. Rathnam, S. Mohite and S. Kumar. Indian J. Chem. Technol,. 15, 409 (2008),

16. P. Vasantharani, V. Pandiyan and A.N. Kannappan, Asian J. Appl. Sci. 2, 169 (2009)

17. A.N. Kannappan, R. Kesavasamy and V. Ponnuswamy, Am. J. Eng. Appl. Sci., 1, 95 (2008).

18. G. Nath, S. Sahu and R. Paikaray, Indian. J. Phys., 83, 1567 (2009).

19. M. Rezaei, H. lloukhani and M. Rakshi, Russ. J. Phys. Chem. A, 84, 2023 (2010).

20. R.J. Fort and W.R. Moore, Trans. Faraday Soc., 62, 1112 (1966).

21. P. Rathore and M. Singh, J. Indian Chem. Soc., 84, 59 (2007).

22. S.K. Pradhan, S.K. Dash, L.Moharana and B.B. Swain, Indian J. Pure Appl. Phys., 50, 161 (2012). 